\title{
Design of Loading and Unloading Machine Hand for Automatic Production Line of Vehicle based on Servo Drive
}

\author{
Zhang Tianhang \\ Southwest Jiaotong University, SIchuan, Leshan614000 \\ 19376251@163.com
}

Keywords : Robot; Mechanical design; Automation; Freedom.

\begin{abstract}
Robot was developed to give a new mean of mechanization and automation of the production process. The design of the robot is used in the automotive automatic production line for loading and unloading of the workpieces. It is from the base, the mechanical arm parts, the wrist rotation parts , and the Interchangeable holder . It possesses a balance of performance properties including:It can capture the object changing the orietation, it can determine the weight of the object , and automatically avoid obstacles, while grasping an empty or insufficient grip strength and other properties can be detected. The robot system mainly consists of three parts: mechanical transmission devices, electrical drives, computer-controlled devices. Mechanical robot body structure using operational body structure, similar to the human arm and wrist, can be coupled with a variety of crawling and a variety of job actions and grasping after the end effector. Technical parameters given by the visible need to use cylindrical coordinates robot. Hand body movement depends on the mechanical structure of the servo drive, which the design is driven by DC servo motor.
\end{abstract}

\section{Introduction}

Industrial machine hand is very difficult to replace the workers to do the flexible operation and needs to work at the judgmental occasions. If we find problems, block and abnormal situations in the operating system, then, the robot can't autonomously identify the correct instructions, and therefore we must close the system. Besides, it requires removing faults before they can operate the operator. Therefore, the workers put forward higher requirements, hoping that the robots can have the vision and touch abilities. The robots could continue to choose the situations to adjust the changing work environment, and the robots could have the "hand - eye" adjustment function. Thus we require that the host could solve a lot of "information", and then it could complete information programming, finally realizing “communication” between human beings and robots.

This kind of robot, through a computer monitor, having some human features, such as "visual”, "touch" functions etc, are called "intelligent robots". The so-called "intelligent" have the abilities of identifying, memorizing, storing and conducting decision-making analysis. In addition, the identifying ability of the robot is achieved by "contacting", "seeing" and "listening" to the human body parts to identify the objects.

Intellectual machine hand is a recent developed technology. The computer technology, monitoring technology, video technology, speech technology, space agencies and bionic mechanical technologies are used in the development and application of the intellectual machine hand. This is another emerging industry that involves modern automatic control system. Due to the development of scientific era, the intelligent robots will take place of the workers to do more work.

\section{Overall Scheme Design}

The Main Content of the Design. Industrial machine hand is a comprehensive production that involves various type of technologies. And it covers mechanical device research, power control, control research and many other researches. To achieve machine movement by itself and make it easy to use, the following is the general design: the aim of the design is that the production machine hand of the manipulation device used on the production line could complete the auto manipulation 
of the mechanical components. The mechanical electrical control device is the actuator that takes self-control as design concept. For the fact that the PLC has unique functions in production industry, the use of PLC monitoring is used to be the electrical control center of in the design.

Main Technical Parameters of the Design.

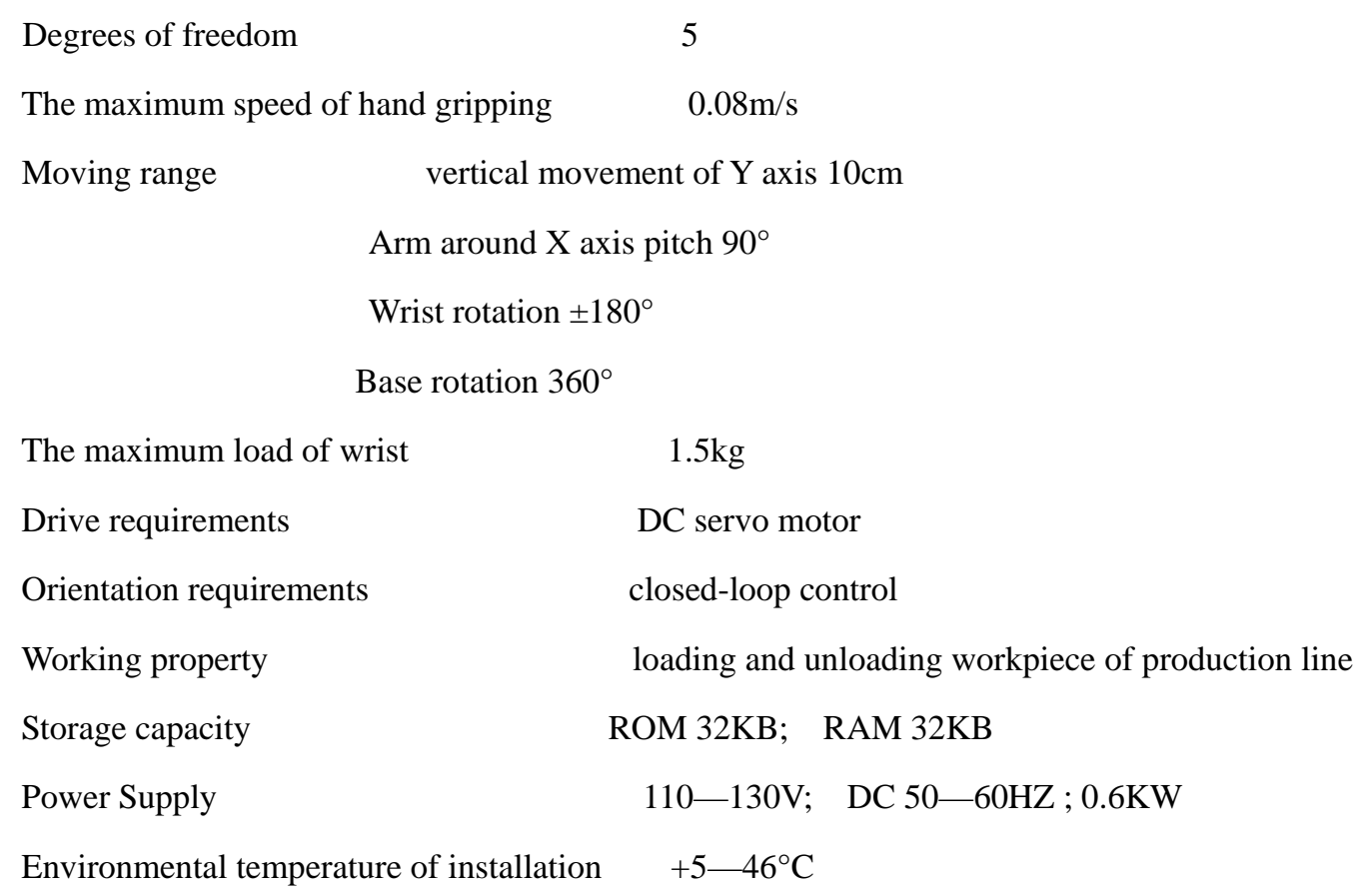

\section{Design of the Mechanical Section}

Transmission Systematic Sketch.

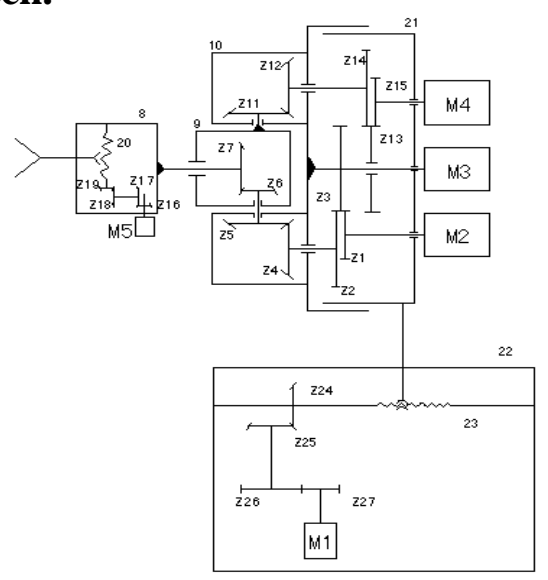

Figure1. The block diagram of the robot transmission system

Rotation Design of Base. The mobile device of industrial robot is loaded on the base, which is the first rotary joint of the machine hand. And the first rotary joint bears the whole gravity of the device.

1. The Characteristics and Principle of the Harmonic Drive. One of the very important components of the base is the harmonic generator, which is driven by elastic deformation to complete the rotation of the new type of transmission machine. In order to complete the transmission operation, it uses a flexible workpiece to work, which breaks the limits brought by the traditional machine with rigid workpiece. Because that there are some other special performance in the design of harmonic reducer that other transmission methods lacks, this invention has been widely used in many fields. In the process of the development of the machine hand, many transfer mechanism uses the harmonic reducer, and the harmonic reducer's obvious merits are out run the 
commonly used system that applied in gear reducer. In calculating, it is required that the base bear all supporting strength, such as some parts of the robot's hand and wrist. So its length is longer that other bases. The use of some other deceleration system can achieve convenient and low-price production. However, the base transverse position is too large, there are more problems and the shape is also significantly heavy. All the above leads to the use problems in internal space of the robot setup.. In addition, the machine hand requires a very high precision, thus, if the base needs to achieve the required accuracy, and a very high stability, the harmonic reducer should be used in the design.

2. The important parts of harmonic gear drive system include:

1) Soft gear. Its diameter of wheel wall is shorter than the long axis of the harmonic oscillator itself, when we use harmonic generator ground, the elastic deformation can be achieved.

2) Rigid gear. Its rigid gear ring has gear teeth, in common condition, there is three-teeth length between the soft gear and the rigid gear.

3) Harmonic generator. By rotating its long axis and short axis of the wheel, we could get desired deformation and make it form regularity

3. The working principle of harmonic generator:

Place the harmonic oscillator into the round hole of a soft gear to deform the big axis of the soft gear's harmonic generator. Elliptic large shaft end and inner rigid gear teeth and the outer soft gear teeth could tightly bite together while the front and back position of the small axis all break up, apart from the above condition, the tooth wheel should be the essential mood type that the tooth wheel is in meshing and disconnecting state. Just when the wheel just fixed, the harmonic generator reverse its rotation to make teeth move at the biting place, which would make the soft gear finish its moving.

The Design and Calculation of the Harmonic Reducer. Design reference: the output rotate speed is $10 \mathrm{r} / \mathrm{min}$, the rotate speed of electronic-controlled engine is $1000 \mathrm{r} / \mathrm{min}$, then

(1) The calculation and check of the soft gear

Roughly compute the work efficiency of the speed reducer:

$$
M=9550 \frac{P}{n}=9550 \frac{0.6 \times 0.85}{10}=48.75 \approx 500 \mathrm{~N} \cdot \mathrm{m}
$$

The output rotate speed of electronically controlled engine is $1000 \mathrm{r} / \mathrm{min}$ 。

1) The pitch diameter and wave height of the soft gear:

Since there is no collision weight, we assume that the engine labor 4 hours a day, and according to 24.44 [11] we can get load bearing ability correction coefficient of 1.0. Besides, we could get the pitch diameter and wave height of the soft gear: $\mathrm{Dr}=150 \mathrm{~mm}$, and $\mathrm{d}=1.5 \mathrm{~mm}$.

2) The determination of the soft and rigid gear's wheel teeth

From $i=100$, input the given generator, and fixe rigid gear, and then output from the soft gear, when the wave number $n=2$,

3) Calculate out the numerical results of the gear

Operate with the harmonic gear tool, we can work out various values of the gear.

$$
\begin{aligned}
& m=\frac{d}{2}=0.75 \mathrm{~mm} \\
& h^{\prime}=\frac{7}{16} d=0.6363 \mathrm{~mm} \\
& s=0.125 d=0.1875 \mathrm{~mm} \\
& D_{G}=\frac{Z_{G} d}{n}=151.5 \mathrm{~mm} \\
& D_{G i}=D_{G}-\frac{7}{8} d=150.1875 \mathrm{~mm} \\
& D_{G 0}=D_{G}+\frac{9}{8} d=153.1875 \mathrm{~mm} \\
& \phi=\arctan \frac{1.09}{n}=28.6^{\circ}
\end{aligned}
$$

$$
\begin{gathered}
t=\pi m=3.14 \times 0.75=2.3562 \mathrm{~mm} \\
h^{\prime \prime}=\frac{9}{16} d=0.8437 \mathrm{~mm} \\
s_{t}=\frac{7}{16} t=1.0307 \mathrm{~mm} \\
D_{R}=\frac{Z_{R} d}{n}=150 \mathrm{~mm} \\
D_{R i}=D_{R}-\frac{9}{8} d=148.3125 \mathrm{~mm} \\
D_{R 0}=D_{R}+\frac{7}{8} d=151.3125 \mathrm{~mm} \\
\varphi_{1}=\varphi+\arctan \frac{0.458 \mathrm{dn}}{r}=29.2^{\circ}
\end{gathered}
$$

4) Calculate out the numerical results of the gear

The determination of various numerical results of soft gear components 
According to 24.4-6 [11] , we can get the thickness of shell of soft gear, diameter of neutral layer of outer soft gear structure and the length of soft gear, they are respectively:

$h_{1}=(0.01 \wedge 0.015) D_{r}=(1.5 \wedge 2.25)$, and we take h1 $=2 \mathrm{~mm}$

$h_{2}=h_{4}=(0.5-0.7) h_{1}=1.4 \mathrm{~mm}$

$h_{3}=0.5 d=0.5 \times 80=40 \mathrm{~mm}$

$r_{m}=\frac{D_{R d}+2 h_{2}}{2}=73.556 \mathrm{~mm}$

5) The specification choice of harmonic oscillator

The thin wall ball bearing type wave generator is applied in the contour for disk cams

6) Sealed applied value $c_{\rho}, c_{r}, k_{m}, k_{\rho}, k_{\tau}, k_{u}, k_{d}, k_{z}$

From 24.4-7[11], we can know $c_{\rho}=2.278 \quad c_{\tau}=0 \quad\left(\beta=0^{\circ}\right)$

From 24.4-8[11], we can know $\quad k_{m}=1.38 \quad k_{\sigma}=2.2 \quad k_{\tau}=1.76$

$k_{u}=1.6 \quad k_{z}=0.7$

For $\mathrm{N}=1000 \mathrm{r} / \mathrm{min}$, which makes the data be more accurate, thus we take $k_{d}=1.1$.

7) Calculate the soft gear stress

According to the above formula, we could get:

$\sigma_{\phi}=k_{m} \times k_{d} \times c_{\rho} \frac{W_{0} E h}{r m^{2}}$

The calculation results: $\quad k_{m}=1.38 \quad k_{d}=1.1 \quad c_{\rho}=2.278$

therefore $E=2.1 \times 10^{5} \mathrm{MP}$, and because $\mathrm{h}=2 \mathrm{~mm}, \quad \mathrm{~W} 0=0.75$

So $\sigma_{\phi}=1.38 \times 1.1 \times 2.278 \frac{0.75 \times 2.1 \times 10^{5} \times 2}{73.556^{2}}=201.33 M P_{a}$

And because

$\tau_{z \phi}=k_{m} \times k_{d} \times c_{\tau} \frac{W_{0} E h}{r_{m} L}$

Because $c_{\tau}=0$, there we take $\tau_{z \phi}=0$

And $\tau_{m}=k_{u} \times k_{d} \times \frac{M_{1}}{2 \pi r_{m}{ }^{2} h}$

Among them $k_{u}=1.6 \quad k_{d}=1.1$

And finally we could get $\tau_{m}=1.6 \times 1.1 \times \frac{500 \times 1000}{2 \pi \times 73.556^{2} \times 2}=12.94 \mathrm{MP} a$

And based on (24.4-5) [11], we could get:

$\sigma_{a}=\sigma_{\phi}=201.33 M P_{a}$

$\rho_{m}=0$

$\tau_{a}=\tau_{m}=0.5 \times 12.94=6.47 M P_{a}$

8) Select the materials, and decide the available stress

The impact load is bigger while we starting soft gear, which needs great alternating stress. Therefore, the precision of chosen materials should be higher.

The carbon content of most of the chosen materials is 30- 45 carbon chromium molybdenum and a series of steel like carbon chromium molybdenum.

Based on 24.4-9[11] and 24.4-10[11],we could choose the following:

The chosen soft gear is $40 \mathrm{CrNiMoA} \quad \sigma_{-1}=500 \mathrm{MP} P_{a} \quad \tau_{-1}=250 \mathrm{MP} a$

The chosen rigid gear is $40 \mathrm{Cr}$;

The chosen intermedium ring is 60Si 。

9) Calculate the permissible operation range $\mathrm{S}$

Based on 24.4-6 and 24.7-7, we can know that:

$$
s=\frac{s_{\rho} s_{\tau}}{\sqrt{s_{\rho}^{2}+k_{\tau} s_{\tau}^{2}}}
$$

In the above design: $s_{\sigma}=\frac{\rho_{-1}}{k_{\rho} \times \rho_{a}}=\frac{500}{2.2 \times 20.133}=1.129$ 


$$
\begin{aligned}
& S_{\tau}=\frac{\tau_{-1}}{k_{\tau} \times \tau_{a}+0.2 \tau_{m}}=\frac{250}{1.76 \times 6.47+0.2 \times 12.94}=17.89 \\
& S=\frac{s_{\rho} S_{\tau}}{\sqrt{s_{\rho}{ }^{2}+k_{\tau} s_{\tau}^{2}}}=8.4>1.5
\end{aligned}
$$

Conclusion: the soft gear could be safely adapted to the operation design.

(2) Design and calculation process of the harmonic generator

1) Based on the design of transmission ratio and the load conditions, we choose thin wall bearing with its outer radius:

$$
D_{n}=D_{R d}=144.3125 \mathrm{~mm} ;
$$

From 24.4-7[11]we could know that the bearing ball diameter $d_{g}=10 \mathrm{~mm}$;

From 24.4-11[11] we could know that:

Choose the thickness range of the outer bearing ring $a_{1} \leq 1.6 h_{1}=1.6 \times 2=3.2 \mathrm{~mm}$

Choose the thickness range of the inner bearing ring $\quad a_{2} \leq 1.8 h_{1}=1.8 \times 2=3.6 \mathrm{~mm}$

The width of the bearing itself $\quad B_{b}=b=30 \mathrm{~mm}$

The depth of the outer ring raceway of the bearing $\quad O_{1}=0.05 d_{g}=0.05 \times 10=0.5 \mathrm{~mm}$

The inner ring groove depth of the bearing $\quad O_{2}=0.1 d_{g}=0.1 \times 10=1 \mathrm{~mm}$

Raceway curvature radius:

$$
\begin{aligned}
& r_{r w}=0.52 d_{g}=5.2 m m \\
& \quad d_{n}=D_{n}-2\left[\left(a_{1}-Q_{1}\right)+\left(a_{2}-Q_{2}\right)+d_{g}\right]= \\
& 144.3125-2[(3.2-05 .)+(3.6-1)+10]=113.7125
\end{aligned}
$$

2) Choose the materials that would avoid the deformation of the soft gear:

If we want to reduce the loss of soft gear wall, and increase its rigidity, and make the load bearing ability larger and the life span of the soft gear longer. We should add a "bending ring" between the soft gear and the harmonic generator. Because the "bending ring" could bear significantly bending stress and contact stress, we finally choose HRC60 material whose rigidity is $60 \mathrm{Si} 2$ with the thickness to be 1.5 times of that of soft gear namely $3 \mathrm{~mm}$.

3.3 Motion Design of Linear Direction of X Axis

If we want the machine hand achieve smooth operation, in this design we should guarantee $20 \mathrm{~mm} / \mathrm{s}$.

It is required to achieve the motor operating performance and mechanical hand sensitivity, so we use the DC servo motor in this design, according to 29-72[4] , we could use:

Electric motor M1 type 90SZ01, and the length of the machine is $124 \mathrm{~mm}$, with the diameter $90 \mathrm{~mm}$, the weight $6 \mathrm{~kg}$ and the capacity factor $50 \mathrm{w}$. The largest turnover number $1500 \mathrm{r} / \mathrm{min}$, total rotation ratio $\mathrm{i}=3$, rotation ratio allocation $2 * 1.5$, the primary reduction applies cylindrical gears rotation with rotation ratio to be 2 , the secondary stage is bevel gear rotation, and the rotation ratio is 1.5 .

\section{General Design and Calculation of Linear Direction of X Axis.}

(1) Rotation speed of each Axis

Motor reel $\mathrm{nl}=1500 \mathrm{r} / \mathrm{min}$

Small cylindrical gear shaft $\mathrm{n} 2=1500 / 2=750 \mathrm{r} / \mathrm{min}$

Big cylindrical gear shaft $\mathrm{n} 3=750 / 1.5=500 \mathrm{r} / \mathrm{min}$

Small bevel gear750 r/min

Big bevel gear500 $\mathrm{r} / \mathrm{min}$

(2) Power of each shaft

The transmission efficiency of cylindrical gear is 0.87 , and that of bevel gear is 0.86 , the results are the following:

$\mathrm{P} 1=\mathrm{P} 0=0.05 \mathrm{kw}$

$\mathrm{P} 2=0.05 ? 0.98=0.049 \mathrm{kw}$

$\mathrm{P} 3=0.049 ? 0.95=0.04655 \mathrm{kw}$

(3) Minimum diameters of each shaft

Based on15-3, the data we could get of the shaft is 39, A1=126-103, take110 


$$
\begin{gathered}
d 1 \geq A 0 \sqrt[3]{p_{1} / n_{1}}=110 \times \sqrt[3]{0.05 / 1500}=3.54 \mathrm{~mm} \\
d 2 \geq A 0 \sqrt[3]{p_{2} / n_{2}}=110 \times \sqrt[3]{0.049 / 750}=4.43 \mathrm{~mm} \\
d 3 \geq A 0 \sqrt[3]{p_{3} / n_{3}}=110 \times \sqrt[3]{0.04655 / 500}=5 \mathrm{~mm}
\end{gathered}
$$

(4) Torque of each shaft

$$
\begin{aligned}
& \mathrm{T} 1=9550 \mathrm{P} 1 / \mathrm{n} 1=9550 ? 0.05 / 1500=0.32 \mathrm{~N} . \mathrm{m} \\
& \mathrm{T} 2=9550 \mathrm{P} 2 / \mathrm{n} 2=9550 ? 0.049 / 7550=0.62 \mathrm{~N} . \mathrm{m} \\
& \mathrm{T} 3=9550 \mathrm{P} 3 / \mathrm{n} 3=9550 ? 0.04655 / 500=0.89 N . \mathrm{m}
\end{aligned}
$$

\subsubsection{Design and Calculation of Cylindrical Gear Reducer}

transmission ratio $\mathrm{i}=2=40 / 20=\mathrm{Z} 2 / \mathrm{Z} 1$, gear modulus $\mathrm{m}=2$, teeth number of small gearsZ1 $=20$,teeth number of large gears $\mathrm{Z} 2=40$. Finally the teeth number of the gears is:

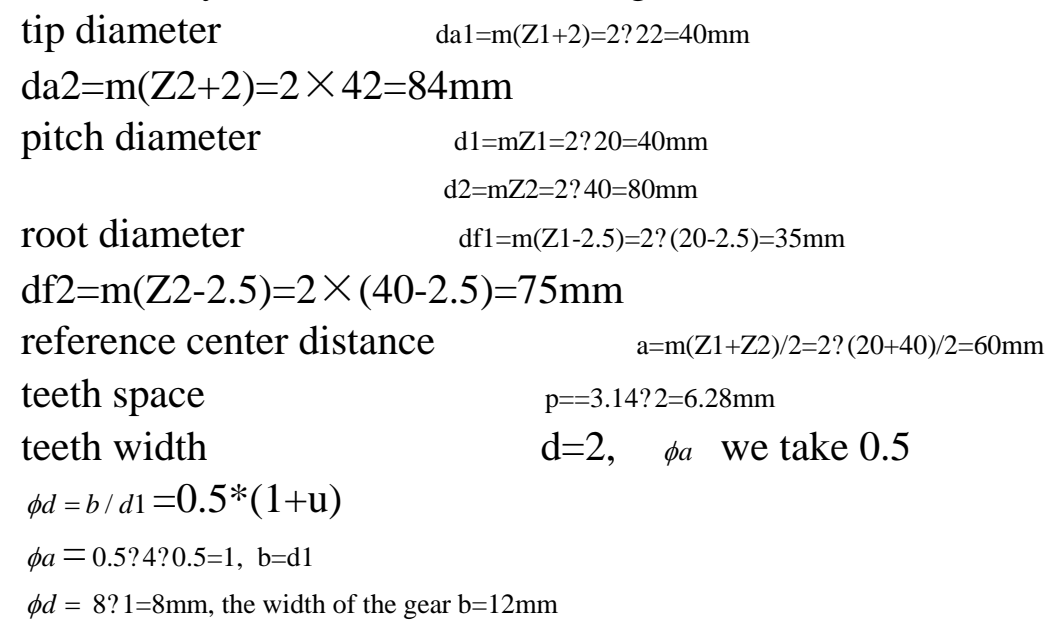

3.3.3 Design and Calculation of the Straight Tooth Bevel Gear

(1)The choice of gear material:

The rated torque of small gear $\mathrm{T} 1=0.62 \mathrm{~N} . \mathrm{m} ; \mathrm{n} 1=750 \mathrm{r} / \mathrm{min}$; big gear: $\mathrm{T} 2=0.89 \mathrm{~N} . \mathrm{m} \quad \mathrm{n} 2=500 \mathrm{r} / \mathrm{min}$, The boat line of the intersection of two gears is $90^{\circ}$, the small gear choose 45 control, hardness of teeth surface is $200-230 \mathrm{HBS}$ the large gear choose 50 control, hardness of the teeth surface is $170-200 \mathrm{HBS}$, based on the median of the values of hardness of the teeth surface, and base on10-20c[8] and10-21d[8] we could get:

$$
\begin{array}{lll}
\text { Small gear } \sigma_{H \lim 1}=565 \mathrm{MPa} & , & \sigma_{F \lim 1}=436 \mathrm{MPa} \\
\text { Large gear } \sigma_{H \text { lim } 2}=540 \mathrm{MPa} & , & \sigma_{F \lim 2}=421 \mathrm{MPa}
\end{array}
$$

(2) Rated gear accuracy level

Based on the design requirements, we choose 8 grade precision

(3) According to the service life of the machine, we choose small gear pitch circle diameter range

$$
d_{1} \geq 2.93 \sqrt{\left(\frac{Z_{E}}{\left[\sigma_{H}\right]}\right)^{2} \frac{K_{T 1}}{\phi_{R}\left(1-0.5 \phi_{R}\right)^{2} u}} m m
$$

In the above equation: we choose the smallest among $\sigma_{H P} 、 \sigma_{H P 1} 、 \sigma_{H P 2}$.

According to mechanical design chart, we could know: $\mathrm{Z}_{E}=189.8 \mathrm{MPa}, \phi_{R}=0.25 \sim 0.35$, and take 0.2 ; loading coefficient $\mathrm{K}=2, \quad \mathrm{~S}_{H}=1 ; \mathrm{N}=3.24 \times 10^{9}$, according to mechanical design chart: $\mathrm{K}_{N}=1$, $\mathrm{u}=1.5$ 。

From the above equation],

$$
\left[\sigma_{H}\right]=\frac{K_{N} \sigma_{H \lim 1}}{S_{H}}=565 \mathrm{Mpa}
$$

therefore, $d_{1} \geq 4.31$, we take $60 \mathrm{~mm}$ 。

(4)Calculate the basic dimensions and parameters of the gear

1) Decide the number of the small gears $z_{1}$ 
According to mechanical design icons and pinion diameter $\mathrm{D}$, the gear surface hardness value is selected as $z_{1}=21$ and $z_{2}={ }_{z_{1}} \times 1.2=25.2$ 。

2) Determine the modulus $m$

$\mathrm{m}=d_{1} / z_{1}=2.873 \mathrm{~mm}$

Judging from 14-3[4]standard value m should be2.857

Calculate the pitch diameters $d_{1} 、 d_{2}$ :

$$
\begin{aligned}
& d_{1}=m z_{1}=2.75 \times 21=57.75 \mathrm{~mm} \\
& d_{2}=m z_{2}=2.75 \times 25.2=69.3 \mathrm{~mm}
\end{aligned}
$$

Calculate the cone angle:

$$
\begin{aligned}
& \delta_{1}=\arctan \left(z_{1} / z_{2}\right)=24.75^{\circ} \\
& \delta_{1}=90^{\circ}-24.75^{\circ}=62.25^{\circ}
\end{aligned}
$$

Calculate the cone space $\mathrm{R}$ :

$$
\mathrm{R}=\frac{m}{2} \sqrt{z_{1}^{2}+z_{2}^{2}}=47.78 \mathrm{~mm}
$$

Calculate the width of the gear:

Coefficient of gear width $\varphi_{R}=0.42$

$$
\mathrm{b}=R \varphi_{R}=47.78 \times 0.42=20.07 \mathrm{~mm}
$$

We take $b=20 \mathrm{~mm}$

Calculate the tip diameter:

$$
\begin{aligned}
& d_{a 1}=d_{1}+2 h_{a} \cos \delta_{1}=5.75+2 \times 3 \cos 33.69=62.16 \mathrm{~mm} \\
& d_{a 2}=d_{2}+2 h_{a} \cos \delta_{2}=69.3+2 \times 3 \cos 69.3=94.08 \mathrm{~mm}
\end{aligned}
$$

Calculate the average circumferential velocity

$$
v_{m}=\frac{\pi d_{m 1} n_{1}}{60 \times 1000}=\frac{3.14 \times 50.52 \times 750}{60 \times 1000}=1.98 \mathrm{~m} / \mathrm{s}
$$

In the above equation $d_{m 1}=d_{1}\left(1-0.5 \varphi_{R}\right)=60.5(1-0.5 \times 0.33)=50.52 \mathrm{~mm}$

\section{The Part of Designing Free Waist.}

According to the design, we set the data:

For the machine hand can be stably move during operating, so we choose the pitch movement of the wrist to be $18 \mathrm{r} / \mathrm{min}$. Electrical motors use $36 \mathrm{SZ01}$, torque to be $170 \mathrm{~g} \cdot \mathrm{cm} \cdot \mathrm{s}$, rotating speed $n_{1}=300 \mathrm{r} /$ min,power to be $5 \mathrm{~W}$, and the total transmission ratio $i=\frac{300}{18}=16.875$. Distribution of transmission ratio: the synchronous belt drop ratio is 3 , cylindrical gear reduction ratio is 2.5 , and bi-cone gear drop ratio is1.5.

1.The Basic Design and Calculation of the Wrist.

(1) The shaft speed

The motor shaft $\mathrm{n} 0=300 \mathrm{r} / \mathrm{min}$

Small cylindrical gear shaft $\mathrm{n} 1=300 / 3=100 \mathrm{r} / \mathrm{min}$

Big cylindrical gear shaft $\mathrm{n} 2=100 / 2.5=40 \mathrm{r} / \mathrm{min}$

Level 1 small bevel gear shaft $\mathrm{n} 2=40 \mathrm{r} / \mathrm{min}$

Level 1 big bevel gear shaft $\mathrm{n} 3=40 / 1.5=27 \mathrm{r} / \mathrm{min}$

Level 2 big bevel gear shaft $\mathrm{n} 4=27 / 1.5=18 \mathrm{r} / \mathrm{min}$

The power of each shaft

$$
\begin{aligned}
& \text { P0 }=0.005 \mathrm{kw} \\
& \text { P1 }=0.005 ? 0.98=0.0049 \mathrm{kw} \\
& \text { P2 }=0.0049 ? 0.9=0.0044 \mathrm{kw} \\
& \text { P3 }=0.0044 ? 0.9=0.004 \mathrm{kw} \\
& \text { P4 }=0.004 ? 0.9=0.0036 \mathrm{kw}
\end{aligned}
$$

(3)The minimum diameter of each shaft

According to the mechanical design table: the shaft material is $45 \mathrm{~A} 0=126-103$, we take 110

$$
d_{1} \geq A_{0} \sqrt[3]{p_{1} / n_{1}}=110 \times \sqrt[3]{0.0049 / 100}=4.03 \mathrm{~mm}
$$

Select $8 \mathrm{~mm}$ 


$$
\begin{gathered}
d_{2} \geq A_{0} \sqrt[3]{p_{2} / n_{2}}=110 \times \sqrt[3]{0.0044 / 40}=5.27 \mathrm{~mm} \\
d_{3} \geq A_{0} \sqrt[3]{p_{3} / n_{3}}=110 \times \sqrt[3]{0.004 / 27}=5.84 \mathrm{~mm} \\
d_{4} \geq A_{0} \sqrt[3]{p_{4} / n_{4}}=110 \times \sqrt[3]{0.0036 / 18}=6.43 \mathrm{~mm}
\end{gathered}
$$

(4)The torque of each shaft $\mathrm{T} 1=9550 \mathrm{P} 1 / \mathrm{n} 1=9550$ ? $0.0049 / 100=0.468 \mathrm{~N} \cdot \mathrm{m}$ $\mathrm{T} 2=9550 \mathrm{P} 2 / \mathrm{n} 2=9550 ? 0.0044 / 40=1.051 \mathrm{~N} . \mathrm{m}$ T3=9550P3/n3=9550? $0.004 / 27=1.415 N . m$ $\mathrm{T} 4=9550 \mathrm{P} 4 / \mathrm{n} 4=9550$ ? 0.0036/18=1.91N.m

\section{Select10mm}

Select $12 \mathrm{~mm}$

Select $10 \mathrm{~mm}$

2 .The Design and Calculation of Synchronous Belt.

(1) Calculate the power: Pc=KAP in this equation, KA-—working state coefficient. By searching the table 14.1-55 in Mechanical Design Handbook, we could know that the KA is 1.40, $\mathrm{P}$ - - power transmission, we could know $\mathrm{Pd}=0.005 \times 1.4=0.007 \mathrm{kw}$.

(2) Choose the belt type and pitch:

According to the design of power and revolution, we should check figure 10-18[4], and table $10-35[4]$, synchronous belt type of the synchronous belt type $\mathrm{XL}, \mathrm{Pb}=5.08 \mathrm{~mm}$ 。

(3)Determine the small pulley gear:

From table 10-40[4], we could know that the smallest number of the small pulley gear $\mathrm{Zmin}=10=\mathrm{Z} 1$

(4) Pitch diameter of the small pulley gear:

$d_{1}=\frac{z_{1} p_{b}}{\pi}=\frac{10 \times 5.08}{\pi}=16.2 \mathrm{~mm}$

(5) Determine the big pulley gear :

$Z_{2}=Z_{1} \times i=10 \times 3=30$

(6) Pitch diameter of the big belt wheel:

$d_{2}=\frac{z_{2} p_{b}}{\pi}=\frac{30 \times 5.08}{\pi}=48.6 \mathrm{~mm}$

(7) tape speed:

$v=\frac{\pi d_{1} n}{60 \times 1000}=\frac{\pi 16.2 \times 300}{60 \times 1000}=0.25 \mathrm{~m} / \mathrm{s} \leq V_{\max }$, so we can put it into use。

(8)The fixed axle spacing for the first time

$0.7\left(d_{1}+d_{2}\right) \leqslant a_{0} \leqslant 2 \quad\left(d_{1}+d_{2}\right)$

$45.36 \leq a_{0} \leq 129.6 \mathrm{~mm}$, there we choose $a=60 \mathrm{~mm}$

(9) The length of the belt:

$L_{0}=2 a_{0}+\frac{\pi}{2}\left(d_{1}+d_{2}\right)+\frac{\left(d_{2}-d_{1}\right)^{2}}{4 a_{0}}=226.11 \mathrm{~mm}$

Check table 10-36[4],we could know that we should choose synchronous belt with its length code to be 90 , and its pitch length $\mathrm{Lp}=4228.6 \mathrm{~mm}$, and the teeth number to be 45 。

(10) The actual shaft space:

$a \approx a_{0}+\frac{L_{p}-L_{0}}{2}=60+\frac{228.6-226.11}{2}=61.2 \mathrm{~mm}$

(11) The basic rated power P0 :

$$
P_{0}=\frac{\left(F_{p}-m v^{2}\right) v}{1000}
$$

From table 14.1-57[4],14.1-58[4], we could know that $b_{\mathrm{so}}=9.5, \mathrm{~m}=0.022 \mathrm{~kg} / \mathrm{m}, F_{p}=50.17 \mathrm{~N}$

So $P_{0}=\frac{\left(50.17-0.022 \times 0.25^{2}\right) \times 0.25}{1000}=0.012 \mathrm{kw}$

(12) The needed width of belt $b_{s}$

$$
b_{s}=b_{s 0} \sqrt[1.44]{\frac{P_{b 1}}{k_{z} p_{0}}}
$$

From table 14.1-58[4] , we could know that $\mathrm{H}$ type belt,bs0=25.4mm, $\mathrm{Kz}=1$ 
So $\quad b_{s}=9.5 \times\left(\frac{0.007}{1 \times 0.012}\right)^{\frac{1}{1.14}}=8.3 \mathrm{~mm}$

(13) The size of tooth profile

$b_{w}=1.32 \pm 0.05, h_{g}=1.65_{-0.05}^{0}, 2 \delta=0.508, r_{b}=0.41, \psi \pm 1.5^{\circ}=25^{\circ}, r_{t}=0.64_{0}^{+0.05}$

(14) The structure and size of the pulley:

From table 14.1-61[4], we could know:

small pulley: $\mathrm{Z} 1=10$, pitch diameter $16.77 \mathrm{~mm}$, external diameter $15.666 \mathrm{~mm}$

big pulley: $\mathrm{Z} 2=30$, pitch diameter $48.51 \mathrm{~mm}$, external diameter $48 \mathrm{~mm}$.

\section{Conclusion}

In this paper, the design topic is design of loading and unloading machine hand for automatic production line. And this design could make the mechanical and electrical components interact with each other. Besides, in the mechanical system the author successfully take the automation system into account, which not only improved the quality of the work, but also reduced the work intensity at the same time. Therefore the design created a better working environment for mankind. Electromechanical integration technology is a high technology that built on the microelectronics technology, mechanical technology, electronic technology, servo drive technology, automation technology, check and sensor technology, the overall system technology and other contemporary high-tech technologies. The important essence of mechanical and electrical integration technology is the comprehensive application of various modern high technologies to design and develop and the application of the methods of system engineering to analyze and study the mechanical and electrical integration products or systems. To sum up, through the organic combination of various technologies, we could complete the reasonable allocation of the internal and external components to finally achieve the best state of the overall effect.

\section{References}

[1] Feng Xin-an. Machinery and Equipment Design [M]. Beijing: Mechanical Industry Publishing House, 2005.12.

[2] Deng Xingzhong. Mechanical and Electrical Drive Control [M]. Wuhan: Huazhong University of Science and Technology Press, 2001.3.

[3] Engineering Drawing Teaching and Research Section of Dalian University of Technology. Mechanical drawing [M]. Beijing: Higher Education Press, 2003.8.

[4] Huang Jichang. Practical Mechanical Agencies Atlas[M]. Beijing: People's Posts and Telecommunications Press, 1996.6.

[5] Wu Zhenbiao. Electromechanical Integrated Design Guidance[M]. Beijing: China Renmin University Press, 2000.

[6] Gu Guan-qun, Wan de-jun. Electromechanical Integration Design Manual (a \& b) [M]. Nanjing: Jiangsu Science and Technology Press, 1996.10

[7] Pu Lianggui,Ji Minggang. Mechanical Design [M]. Beijing: Higher Education Press, 2001.

[8] Guo Qiquan. Application and Development of Tutorial of AutoCAD2002 [M]. Beijing: Mechanical Industry Press, 2002.11. 